\title{
Does scientism undermine other forms of knowledge?
}

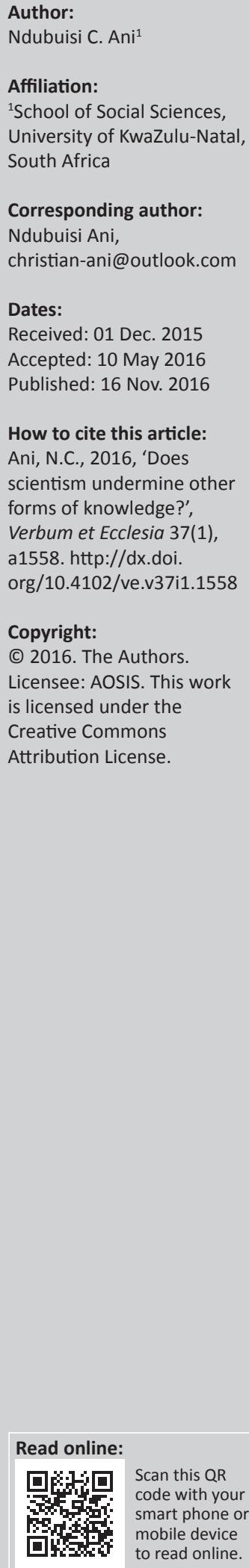

Science has continually bridged the gaps in knowledge about reality by exerting its prowess in explanation, discovery and invention. Astonished by the successes of science coupled with the demonstrability and (purported) objectivity of scientific knowledge, scholars are lured to nurse the impression that science is the answer to all questions that need to be asked about reality. This has led to an intellectual fanaticism called scientism where science is seen as the only bona fide way of attaining any true knowledge whatsoever. Consequently, other fields of knowledge suffer grievously from being abandoned, belittled or modified to operate using the scientific method of inquiry. Against this backdrop, this paper argues that science is not the only way of knowing reality. Other fields of knowledge and their traditional methods of inquiry are vital in the understanding of reality that abandoning or constructing them in the scientific light is tantamount to having a parochial view of reality. Through its arguments, the research advances pluralistic, inclusive and complementary approaches.

Intradisciplinary and/or interdisciplinary implications: This research challenges the claims and influence of scientism, which holds that science has the answer to every question about reality. The paper contends that other epistemological methods of philosophical, religious, mythical and artistic forms are essential epistemological methods. Hence, the research advances a pluralistic and complementary approach in epistemology.

\section{Introduction}

This research contends with the scientistic claim that science holds the answer to attaining true and indubitable knowledge. The study is premised on the consideration that the apparent objectivity and demonstrability of scientific knowledge, coupled with remarkable scientific discoveries and inventions, continue to nurture a fanaticism dubbed scientism which holds that science is the answer to all questions that need to be asked about reality. Consequently, other fields of knowledge suffer from being abandoned, belittled or modified to operate using scientific methods of inquiry. It becomes essential to understand the purported objectivity of science and the extent to which it undermines other forms of knowledge.

Science as it is known at present emerged during the period of Renaissance ${ }^{1}$ as a separate discipline from philosophy. Prior to that, every form of intellectual inquiry was reckoned a philosophical quest. There was no dichotomy between what was called science at the time and philosophy. As a branch of philosophy, science was based on speculation and intuition of the essential properties of nature and the natural purposes of things in tandem with Aristotelian physics (O'Hear 1989:12). At this time, scientific theories and hypotheses were untested because thinking was the proper way of acquiring knowledge. Hawking (1988:15) notes that 'the Aristotelian tradition held that one could work out all the laws that govern the universe by pure thought alone'. The physics of Aristotle (384-322) dominated as the authoritative method used in scientific inquiries for 2000 years spanning from the 3rd century BCE to the 17th century CE at the wake of Renaissance.

With the dawn of the Renaissance era in the 16th century CE, a deep-seated quest for certainty in knowledge arose in scholars and they resorted to reliance on experiential knowledge. Instead of speculating about reality, Renaissance thinkers desisted from abstract traditional theories by delving into knowing and mastering natural phenomena by empirically demonstrating facts by experimentation with curiosity and desire for impartiality. Thus, in the 17 th century CE, a scientific revolution occurred and a new form of science emerged to confute and demean the scientific authority of Aristotelian science. The heralds of the emerging science laid great stress on observation and experiment as the means of obtaining information about reality. Advancement in

1.Renaissance means 'rebirth' or the enthusiasm in literary and cultural movements in Europe, which led to the reformation of religion, arts and science, around the 14th, 15th and 16th centuries (Solomon 1996:163). 
mathematics coupled with the invention of various special apparatus like telescopes, microscopes, amongst others, expedited their observation and experiments in the pursuit for certainty and control of natural phenomena (Copleston 1963:89). Empirical observation and mathematical reasoning turned out to be the chief scientific methods of enquiry.

Since the new sciences did not rely primarily on speculation, a widened gap developed between philosophy and science which eventually led to the bifurcation that is extant between them today. Some areas of interest in philosophy were singled out by heralds of science for specialised scientific inquiry (Copleston 1963:86). Philosophical interest areas like natural philosophy gave way to physics, philosophy of organism to biology, philosophical psychology to scientific psychology, amongst others. At this point, science began to gain autonomy from philosophy, as particular sciences began to be identified independently from philosophy. Copleston (1963:86) notes that everything that can be definitely known with conviction came to be considered to fall within the province of the sciences. On the contrary, philosophy came to be regarded degradingly as a conjectural study of abstract questions.

Sir Isaac Newton (1643-1727), a great mathematician and experimental physicist, arose as an exceptional scientist who established classical science. Newton introduced an inductive method of scientific inquiry that began with the 'careful inquiry into the properties of things, and establishing those properties by experiments and proceeding to make hypotheses for the explanation of them' (Neill 1958:153). Using his inductive method of inquiry, Newton discovered the three famous laws of motion and the law of universal gravitation that govern the motion of both celestial and terrestrial bodies. With these laws, he gave a mechanical explanation of the motion of the earth, the stars and the moon coupled with their effects on one another (Solomon 1996:191). His aim, as championed in Principia (Newton 1987), was to show that the universe is governed by immutable scientific or mechanical laws in which everything has its determinate and determining course. With the great successes of the Newtonian mechanical model of the universe, people began to nurture the idea that the science of mechanics could do everything. Whatever could not be mechanically explained was considered unintelligible. In this vein, some scholars such as Pierre Simon de Laplace argue that scientific laws could predict every phenomenon in the universe including the behaviour of human beings (Hawking 1988:53).

Over the years, renowned scientists such as Albert Einstein, Edwin Hubble, Georges Lemaitre, Charles Darwin, Richard Hawking, amongst others, gave prestige to science by advancing scientific theories and discoveries. Theories and discoveries such as the Big Bang and evolution theories further stretched human minds beyond the common sense explanation of the existence and origin of things. Scientific endeavours have led to a huge advance in technology which makes our lives and work much easier, thereby giving science a significant influential role in societies.
Astonished by the successes and advances of science coupled with the systematic accuracy and purported objectivity of scientific knowledge, some scholars like Augustus Comte and Richard Dawkins nurse the feeling that science is the answer to all questions that need to be asked about reality (Midgley 2006:13). Such impression has led to an intellectual fanaticism christened scientism - a view that maintains that scientific methods are the only genuine means of acquiring indubitable knowledge about reality thereby belittling other forms of knowledge. A number of studies have challenged the impression of the infallibility of scientific knowledge (Gleiser 2014; Jaki 2000; Midgley 2006; Polkinghorne 1996). There however remain limited studies that link the discourse to the credibility of other forms of knowledge.

This study thus engages with the veracity of scientism by critically examining the purported objectivity of science in relation to other forms of knowledge. The paper contends that the reliability of scientific methods of inquiry are riddled with aspersions as other forms of knowing. Other fields of knowledge and their traditional method of inquiry are vital in the understanding of reality that abandoning or constructing them in the scientific light is tantamount to having a parochial view of reality. To this end, the paper is divided into three major sections. The following section titled 'Scientism and its influence' engages with the comprehension and influence of scientism on philosophy and ideologies. While recognising the significant role of science in the contemporary world order, the next section dubbed 'A critique of scientism' looks into the nature and limits of science so as to refute the claims of scientism. The study culminates with an exploration of the relevance of other means of knowledge, namely philosophical, religious and artistic knowledge.

\section{Scientism and its influence}

Lehar (n.d.) describes scientism as:

the belief that the methods of science are not only appropriate for discovering physical truths, but also for all other truths, including those traditionally treated in philosophy, ethics and morality, political and cultural philosophy, and the rights and wrongs of human interaction. (p. 2)

Here, science is deemed to have the ultimate and authoritative interpretation of reality that is superior over every other form of interpretations whatsoever. If any true knowledge is to be attained at all, the scientific method of inquiry is considered the best way of explaining reality meaningfully. Since science entails a systematic knowledge attained through empirical procedures, anything that cannot be empirically verified is deemed irrational, nonsensical and unworthy of being referred to as knowledge at all. Hence, scientism reduces the whole of reality to experiential material entities.

The tenets of scientism extend to the notion that scientific method has no limits and can explain and solve the problems of the world if applied in all facets of life. Hence, every other way of knowing is expected to model itself on the scientific 
way of knowing. Impelled by the spirit of scientism, Otto Neurath (1882-1945) and Rudolf Carnap (1891-1970), who were members of the Vienna Circle, unanimously agree that science is the paradigm of rationality and that 'there is no field into which scientific research can never carry any light', there is no limit to science (Sorell 1991:6). That is to say that all fields of enquiry can be perfected by the panoptic principles of natural science so as to ensure the acquisition of genuine knowledge. Indeed, many scholars have been lured into practicing philosophy, sociology, politics and business using scientific method of inquiry. Yet, they have ended up making delusory claims since they apply methods unsuitable for their peculiar fields of knowledge.

\section{The influence of scientific methods on philosophy}

With the dawn of the scientific revolution, philosophy seemed unprogressive and disfavoured amongst scholars. Modern philosophers were deluded into thinking that the scientific method of inquiry can be applied in philosophy in order to yield fruitful results like that of science. Thus, they subjected their philosophical thoughts to observations, mathematical calculations and mechanical laws. Some of the famous philosophers that were swayed by the scientific methods of inquiry were Descartes, Spinoza and Kant. This section elucidates how mathematics and geometry influenced Descartes and Spinoza, and how the progress of science especially Newtonian science - had its bearing on Kant.

Rene Descartes (1596-1650), an outstanding rationalist philosopher and mathematician, was greatly influenced by scientific thinking - mathematics in particular - in his philosophical inquiries. In his years of study under the tutelage of the Jesuit College of La Fleche, Descartes was deeply disappointed with philosophy because it was not yielding the clear and distinct knowledge he ardently sought. Believing that philosophy is degenerate and full of doubtful and uncertain terminologies and ideas, he set out to reconstruct it (Sorell 1991:3). Based on the emphasis of the new science on clear and indisputable demonstration of knowledge, Descartes contended that we ought to establish the veracity of metaphysical ideas and beliefs. Thus, Descartes (1641:112) sought for a system of true propositions in which nothing that is not self-evident and indubitable is presupposed.

Descartes found mathematics impressive, self-evident and unquestionable because of its clarity, distinctiveness and precision. For instance, it can hardly be doubted, based on empirical evidence, that a square has four sides. In his quest for a right method of philosophising and acquiring knowledge, Descartes resorted to mathematics, intending to make all of knowledge 'a universal mathematics' (Stumpf 1982:231). Just as mathematics provides 'certainty' in knowledge, so also must other fields of knowledge, philosophy in particular. He saw in mathematics how people progress in an orderly way from what they know to what they do not know. Here, mathematics guides scholars step by step to discover new truth from the knowledge of some basic or self-evident truths.

Thus, in philosophy, Descartes uses his methodic doubt to discover a self-evident truth that would enable him progress step by step to discovering other new truths (Gilson 1963:61). Here, he doubted everything until he surmised that the mind is the certain self-evident and axiomatic truth because he could not doubt that he thinks using his mind. Hence, he exclaimed 'Cogito ergo sum (I think therefore I am)'. To give credence to the certainty of his reasoning, Descartes claims that the existence of God legitimises his clear and distinct ideas. Consequently, Descartes' over-dependency on mathematical reasoning and certainty led him to being involved in an epistemological blunder called circular reasoning. His circular reasoning has to do with assuming the reliability of his clear and distinct idea of God to justify the reliability of the clear and distinct ideas of his mind. Descartes also ended up regarding the human knower as a pure spirit - angelic knower - rather than an embodied spirit, an incarnate knower.

Baruch Spinoza (1633-1677), a Jewish philosopher, was also induced by the influence of scientific methods of inquiry. He was particularly influenced by the thought patterns and methodologies of Francis Bacon and Descartes. For Spinoza, the genuineness of knowledge depends on its logical necessity as obtainable in geometry (Sahakian 1968:141). By mathematical demonstration - geometric method - Spinoza literally wrote a geometry of philosophy entitled Ethics Demonstrated in a Geometrical Manner, a complete set of axioms and theorems that would explain the whole structure of reality parallel to the way geometry gives details of the relations and movements of things (Solomon 1996:188). For him, God is first in priority to the other of things. In fact, God is the only substance there is; God is nature and nature is God (Collinson 1987:61). He claims that just as a triangle must have properties, so also does nature constitute the properties and modes of God. Hence, the existence of the world is only a logical necessity of the existence of God. Against this backdrop, he went on using theorems and axioms to explain reality in turns beginning with God, the nature and origin of the mind, the origin and nature of the emotions, freedom, amongst others. With his geometrical terms, he shows how everything is related and connected to God, the only substance par excellence.

Immanuel Kant (1724-1804), a German philosopher, was also enticed by science and its progress. He was enthralled by the Copernican Revolution which brought about a successful paradigm in the scientific field. ${ }^{2}$ Thus, he reasons that he could introduce a similar revolution in philosophy which would turn out to be true and fruitful in the philosophical

2.During Galileo's time, the Aristotelian-Ptolemaic theory of the universe was the paradigm on which the universe was conceived. This geocentric theory saw the earth as the centre of the universe and every other celestial body was opined to be in circular motion around it (Collinson 1987:47). In his book On the Revolutions of the Heavenly Spheres (1543), Nicholas Copernicus (1473-1543) posited radically the Heavenly Spheres (1543), Nicholas Copernicus (1473-1543) posited radically
that the sun is the centre of the universe - heliocentric - and that the earth was that the sun is the centre of the universe
simply one of the planets orbiting the sun. 
realm. Kant was specifically interested in Newtonian science because it gave him a clear direction on how to introduce his own Copernican Revolution in the philosophical realm. Kant observes that in Newtonian science a priori knowledge is acquired from imposing judgements like cause and effect, space and time, on the things observed (Kant 1929:54). ${ }^{3}$ Here, we experience things and deploy reason to make judgements on them based on some abstract intra-mental categories of thought.

Hence, Kant asserts that what happens in scientific knowledge and every form of knowledge whatsoever is that the mind imposes some 'categories of thought' or 'forms of intuition' on reality or the objects known. In line with Newtonian science, Kant postulated his Copernican Revolution by asserting that things conform to the mind contrary to the traditional epistemological notion that the mind conforms to the thing known (Jones 1975:19). Here, knowledge consists in the obedience of things to the forms of intuition existent in the mind. The categories of thought become inevitable spectacles that determine how reality is perceived. Kant regards space and time, quantity, quality, relation and modality as forms of intuition that are imposed on things to be known.

Consequent on the notion that things conform to the mind's categories of thought, Kant argues that there are two kinds of reality, phenomenon and noumenon (Kant 1929:266). Phenomenon is a thing as it appears when the forms of intuition have been imposed on it. Noumenon is the thing-initself which cannot be known because the categories of thought in our mind always impose themselves on the object of knowledge. With the sway of Newtonian science in his thinking, Kant ended up limiting the scope of human knowledge to the phenomenon. If his deductions are to be followed, we are forever hindered from knowing things as they really are.

\section{Influence of scientism on ideologies}

Scientistic-minded scholars have found it apt to reduce all of reality to a physical phenomenon. For instance, Ernst Haeckel (1834-1919), a biologist and a material monist, typifies the scientistic conception of reality when he insists that there are no realities such as God, immortal soul, free will, amongst others. For him and his ilk, physical reality is all there is. Everything - including complex realities like the human mind and sensation - can be explained in terms of 'the evolutionary development of material substance' (Jones 1975:199). Here, human minds are conceived simply as a corollary of the physical complexity of the human body systems. As such, the complexity of the act of human understanding turns out to be a mere physical operation. ${ }^{4}$

3.Newton's aim as championed in the Principia (1987) was to show that the universe is governed by immutable scientific or mechanical laws in which everything has its determinate and determining course (Copleston 1960:186).

4.Augustus Comte (1798-1857), a sociological positivist, and his followers holds that social behaviour, including the character and morality of a person, could be observed and measured scientifically (Dauben 1987:170).
The dawn of the magnum opus by Charles Darwin On the Origin of Species in 1859 incited philosophers like Herbert Spencer (1820-1903) to postulate that the entire universe is ascending towards ultimate perfection under the guidance of some inescapable natural laws (Alexander 2008:175). ${ }^{5}$ Spencer synopsised Darwin's notion of natural selection as 'survival of the fittest' and this notion insidiously crept into social lives. Spencer claims that only the well-adapted (powerful and successful) individuals in society are capable of surviving and reproducing. The individualism that has plagued the world today has resulted from a supposed realisation of each person as an autonomous ultimate unit in full charge of his or her survival and destiny in line with the 'survival of the fittest' perspective. Society becomes a mere conglomeration of individuals selfishly seeking their own interests (Midgley 2006:10). Basically, only the economically fit individuals are the ones considered to be favoured by the law of nature, survival of the fittest. Hence, people feel impelled to do whatever it takes to be economically fit even at the expense of others.

In support of colonialism and racism, Spencer contends that different races were undergoing different stages of cultural evolution which makes it permissible to view some races as slow pacers and inferior to others, the fast pacers (Alexander 2008:177). Along such thinking, Selous F C insists that 'blacks should either accept the white man's rule, or die in trying to resist it' (cited in Alexander 2008:176). That is to say that the whites are going out of their way to engage in a charitable service of colonising and raising up the black race (slow pacers) to their superior standards through colonialism. Hence, the blacks should be grateful for that so-called charity or else bear the risk of extinction since it is only the 'fast pacers' who can survive the demands of nature.

During the first half of the 20th century, the concept of 'survival of the fittest' came to be adopted in support of eugenics aimed at eliminating 'unfit people'. The United States, Nazi Germany, and several other countries enacted a compulsory sterilisation statute to sterilise confirmed criminals; idiots; rapists; imbeciles; schizophrenics; people with manic depression, hereditary blindness or deafness; and severe alcoholics who have been pronounced incurable (Alexander 2008:179). Marriages between those with mental defects were prohibited too. Eventually, eugenics went through a slippery slope from the elimination of unfit people to the elimination of some group of people as seen in the awfulness of Hitler's holocaust.

5.In his On The Origin of Species (1859), Charles Darwin (1809-1882) delineated how the variety of living things came to be through a process of random mutation summarised as natural selection. Having read the essay on the Principle of Population by Thomas Malthus (1766-1834), Darwin reckoned that populations or species grow prolifically to exceed available food resources (Barrett 2000:88) Owing to the competitive condition necessitated by the paucity of food resources, the organisms with beneficial variations are more likely to survive, grow to the organisms with beneficial variations are lore adulthood and reproduce. Darwin - as well as Alfred Wallace (1823-1913) - noted that the scarcity of food resources and the beneficial variations being transferred from one organism to another, over a long period of time, result in remarkable changes within a given species and sometimes a new species emerges distinct from its original species (Barrett 2000:92). Darwin dubbed this arbitrary process as 'natural selection', a process through which living things modify and develop into complex beings to meet up with the demands of living. 
Furthermore, scientific theories such as the Big Bang theory ${ }^{6}$ and the evolutionary theory ${ }^{7}$ provided divergent account of existence which is based on chance as opposed to the conception of the deterministic and purposeful creation of the universe by God. While evolutionists see human beings as merely 'children of genetics and environmental necessity' (Miller 1999:2), Big Bang theorists content that we are simply products of mere chance and there is no place for a creator hypothesis (Hawking 1988:116). Besides, the Big Bang theory estimates that the universe would come to an end at about 100 trillion years to come through a process called Big Crunch or through a Big Rip. ${ }^{8}$ Thus, human beings who conceive themselves as the special and unique work of God's miraculous deeds are now confronted with scientific facts that ostensibly demean their place in the universe and raise questions as to the existence of a Supreme Being. For atheists, the concept of the supernatural becomes archaic since science can explain everything without subscribing to any supernatural entity. Augustus Comte contends that 'science could yield positive knowledge which displaces the earlier more primitive and mythological attempts of religion and metaphysics to provide systems of thought for coping with experience' (O'Hear 1989:202).

For Richard Dawkins, an atheist and staunch exponent of scientism, 'the need for God as an explanation for the existence of the universe is a relic of humanity's intellectual childhood and nothing more' (Miller 1999:8). In his work entitled The God Delusion, Dawkins (2006:99) sets out to prove that there is no Supreme Being to certify religious beliefs. For him, the universe is purposeless and born out of utter chance, and science alone can unravel the mysteries of the universe. Thus, the idea of God and religion is a delusive means of escaping reality. Some other atheists however permit religion only based on its functional role of relieving people of distress and stress-related diseases. Yet, in reality, it is deemed illusory and baseless since there is allegedly no supernatural reality that makes it credible. Based on the foregoing, the following section titled 'A critique of scientism' critically examines the nature and limits of science in response to the claims of scientism.

\section{A critique of scientism}

The tenets of scientism are enticing because they provide an overly simplified version of reality that is tied to matter.

6. In the light of quantum mechanics and the theory of relativity coupled with the theory (Hawkin 1988:31). The Big Bang theory, as championed by Georges Lemaitre (1894-1966), held that the universe and all it contains are products of the explosion of primordial atom that has been expanding and cooling since about 14 billion years ago (Carlo 1967:148).

7.The theory of evolution holds that out of the cataclysm of transient action, the tumult of forces of nature, scorching temperatures and crushing pressures arose the original germ of life from non-living matter (Carlo 1967:115). The gradual modification of this one germ of life gave rise to the variety of living things we experience. Over millions of years, simple elementary forms of life developed gradually to higher and more complex forms of life in order to adapt to variable and graduallo descended from a common ancestor.

8.While the Big Crunch has to do with a stoppage of the expansion of the universe, a gravitational contraction and a reversal of the Big Bang, the Big Rip suggests the escalation of the expansion of the universe beyond limit. In terms of the latter, the escalation of the expansion of the universe beyond limit. In terms of the latter, the
electromagnetic force would be overcome and everything would be torn apart (Hawking 1988:115).
The whole of reality becomes reduced to quantifiable and factual material entities that can be easily confirmed by sense experience. The transposition of scientific theories into the framework of other fields of knowledge and into societal lives shows how scientific endeavours can be and have been abused by scientistic-minded scholars. Jaki (2000:9) notes that if scientism were to be true, we are bound to subscribe to the advice given by David Hume at end of his Enquiry Concerning Human Understanding by burning all books except those that contain quantities and matters of fact. The scientistic reductionist perspective of reality as constituted of matter alone is merely an attempt to atomise, tame and simplify reality so as to circumvent issues beyond science. It is important to note that science does not harbour the claims of scientism as its principle. Rather, observers or fanatics who are overwhelmed by scientific successes, accord science superior and perfect status as contained in the worldview called scientism.

\section{The nature and limits of science}

Science is the systematic study of physical and natural phenomena through careful observation and experiment. 'Science is competent wherever and whenever the object of investigation offers a quantitatively determinable aspect' (Jaki 2000:5). Its inquiry extends to all matter whether solid, liquid, gas or a mere flow of energy waves. Vis-à-vis matter, science possesses authoritative stands in its statements. Polkinghorne (1996:3) holds that 'the most impressive aspect of science is its ability to provide satisfactory answers to the questions that it asks'. Due to its verifiability, science arrives at answers that can be inter-subjectively verified and understood by people in various parts of the world. However, to claim that science can explain the whole of reality and that its method of inquiry can be used in other fields of knowledge is to provide an impoverished account of reality.

Science uses the method of induction to accumulate facts, make general laws and make prediction of future phenomena from the observation of particular facts. Here, nature is understood to be obedient to certain uniform sets of laws which are adjudged to be the same in the past, in the present and in the future (Carlo 1967:31). For instance, a scientific induction states that all planets in the universe have elliptical orbits. Scientific empiricists claim such scientific induction is objective and universal because it can be verified through experience. However, Karl Popper (1902-1994) argues aptly that it is impossible to verify a universal or general proposition by reference to experience (Popper 1972:28). To make a universal proposition, one has to experience all the examples of a thing in question. However, it is not viable to claim that one has exhausted all the possibilities and examples of a particular thing - for example, all planets - as a basis for generalisation. Hence, the aforementioned generalisation is not objective and indubitable since it can be falsified by a single observation of a planet in the universe which may not have an elliptical orbit. Consequently, the nature of the scientific method of inquiry inevitably means that science can only obtain probable or approximate knowledge of some particular facts. 
Authors such as Polkinghorne (1996:6) maintain that it will be illusory to hold obstinately that future behaviour would be guided by past experiences. For instance, it is not enough to claim that since the sun rose today, it would rise tomorrow. In this vein, it is only a matter of probability that the experiment conducted at a particular space and time will yield the same result at another space and time. Belief and hope becomes the basis for arguing that the conditions that gave rise to a certain outcome will the same in the future. Thus, science makes sense of reality based on belief just as in religious, mythological, common sense and other forms of knowledge (Ani 2013:310).

Furthermore, it is worth noting that the heralds of science, such as Francis Bacon, had imagined that science will base its explanations primarily from empirical data without speculations. In accord with such view, logical positivists hold that science only develops theories after empirical observations. Prominent scientists such as Thomas Kuhn (1922-1996) - as well as Paul Feyarabend (1924-1994) however argue that every scientific observation is reliant on beliefs, assumptions and problems of a particular space and time (Kuhn 1962:53). The problems and things that need focus in societies, for example, the problems of cancer, HIV and/or AIDS, security, amongst others, as well as the efforts to solve those problems, determine and direct scientific observations (Ani 2013:304). Along this line of thought, O'Hear (1989:16) maintains there can be no empirical observation without some unverified and untested assumption and ideas regarding the nature of the things to be observed. A scientist making observations would choose to focus on some aspects of a thing and ignore some other facts because he or she inevitably has some idea of what should be observed. Hence, background theories, myths, biases and beliefs of scientists reflect in scientific observations and judgements about reality.

Contrary to the view of scientific realists that science aims at acquiring certainty in knowledge and truth about reality, Popper insists that science is not really a quest for certainty in knowledge. Rather it is an evolutionary process where hypotheses are imaginatively proposed and tested so as to solve problems (Thornton 2008). For him, science is not a quest for truth rather it is a problem-solving enterprise that is capable of changing its claims in the face of additional facts. Here, when a scientific paradigm fails to solve some important anomalies that accrue over time, scientists search for another paradigm that works. Here, scientists keep changing their conception of reality in a bid to solve problems at hand.

Moreover, it is probable that since scientific theories are sometimes mistaken and abandoned over time, it is possible that present day theories may be obsolete in the future (Audi 2003:263). For instance, the mechanical or absolute conception of reality in classical science as espoused by Newtonian physics was abandoned for the theory of relativity in modern science. Contrary to the Newtonian mechanical model of nature, Heisenberg's indeterminacy principle shows that one cannot easily predict the movement and position of atomic particles (Hawking 1988:54). With this, scientists abrogated the Newtonian mechanics and came up with the quantum mechanics to accommodate the non-regularity in atomic elements. Moreover, in negation of Newton's idea that every phenomenon is absolute for everyone at all times, Albert Einstein (1879-1955) - a renowned physicist - came up with the theory of relativity to show that 'observers in different frames of reference give different descriptions of specific events despite the identical descriptions of the laws that govern those events' (Hazen 1996:158). Capra (1982:63) notes that the quantum theory and the theory of relativity gave modern science a more subtle, holistic and realistic view of nature.

A number of concepts in classical science such as atom, mass and force have undergone revisions in such a way that their present-day meanings are incompatible with their earlier meanings (Ani 2013:312). It is then possible that the scientific assumptions of present-day scientists could be falsified by new findings in the future. In accord with Gleisser (2014), the island of ignorance expands as the islands of scientific knowledge expands. Hence, to claim the perfection of science or the conclusiveness of scientific findings is to argue against the foundational disposition of science which entails making discoveries and growing beyond present knowledge of natural phenomena. Contrary to the tenets of scientism, science cannot claim irrefutable knowledge or truth (Jaki 2000:5). Scientific knowledge then serve pragmatic purposes at a particular space and time until they are advanced, refuted or revised based on future findings.

Having considered the limitations of scientific methods of inquiry, some scholars insist that the successes of science make the scientific method of inquiry superior and subject to be adopted by other fields of knowledge. However, it is pertinent to note that it is within the domain of science to be productive and successful as it does due to its particular object of knowledge and method of inquiry. Kant observes that we err when we expect philosophy - and other fields of knowledge - to give the kind of results that science gives (Copleston 1963:86). Science only plays its own role in the world. Successes in other fields of knowledge are measured differently from the way the successes in science are measured. The following sections attempts to justify the validity of knowledge acquisition in other branches of knowledge such as philosophical, religious as well as artistic knowledge in relation to science.

\section{Justification of the validity of other fields of knowledge}

In view of the limitations of science already examined, scientistic claims prove to be alternative mythologies geared towards understanding the complexity of reality in a simple and easy way. Polykarp Kusch, a Nobel-Laureate physicist, insists that 'science cannot do a very large number of things, and to assume that science may find a technical solution to all problems is the road to disaster' (Jaki 2000:21). With the dynamism and wide ranging feature of the human intellect 
and the bountiful treasure of things to be known, there ought not to be any particular way of knowing that should monopolise and limit the human capacity to know. Other fields of knowledge and their traditional means of inquiry are so vital in the understanding of reality that abandoning or constructing them in the scientific light is tantamount to having a parochial view of reality. The study thus explores the grounds for the validity of other fields of knowledge like philosophical, religious, poetic and artistic knowledge.

\section{Philosophical knowledge}

Philosophy is the study of all things that can be known in their ultimate causes and universal principles under the light of natural reasoning (Sanguineti 1987:6). Philosophical reasoning stems from the dynamism of the human intellect's quest to know things in their totality, looking at the bigger picture of reality. Through reasoning, philosophical disciplines consider all aspects of reality and experience of life - material and non-material, spiritual and non-spiritual in order to acquire a reliable philosophical knowledge. Science and other fields of knowledge that deal with particular aspects of reality are limited to a particular point of view. However, philosophy puts the whole of reality into perspective in order to make its judgements. It reflects and speculates upon the disparate data known from the various sciences and other fields of knowledge and it endeavours to make meaning out of them.

Scientists use concepts like existence, life and causality but they cannot claim to know what those concepts mean scientifically. With regard to life, for instance, 'biochemists, biophysics etc can show enormous extent of measurable parameter in life processes but they cannot in any way measure life itself' (Jaki 2000:10). With regard to causality, no scientist has ever observed causality. It is only by recourse to metaphysics, that scientists and non-scientists reason that any succession of events is a sign of causal interaction (Jaki 2000:95). These show that science is ineluctably limited as soon as a question that cannot be put in quantitative form arises because it deals only with material entities. Suffice it to say that it is not within the jurisdiction of science to understand concepts like life, causality, existence and many other intangible realities. It is the onus of philosophical disciplines to grapple with these issues and enhance knowledge in such areas.

Ethics, which is a philosophical discipline, aims at ascertaining the standards and principles of moral conduct. Here, societal beliefs, intuition, reason, experience and values add up with other factors to determine moral knowledge and judgement of what is right or wrong. It is not the object of science to provide moral knowledge. Science is often oblivious of ethical issues since it is specialised in probing material reality. Hence, although science has been valuable and very useful in society, it has also been used as a destructive tool in history (Hummel 1986:17). It does not consider whether what it produces or experiments on is right or wrong. Over the years, because of the lack of ethical concerns in science, human beings, animals and nature as a whole have been abused.
Scientific adventures contributed to the making of weapons of mass destruction that serve vicious ends such as atomic bombs, guns, nuclear weapons, thermonuclear bombs, amongst others. It has led to the production of sophisticated machines used in industries, which have led to ecological destruction and the global warming palpable on earth today. Human lives and the lives of animals lose their dignity by being used for scholarly examination, experiments and modification in the medical fields. In view of the ethical limitations in science, other fields of knowledge like religion, ethics and sociology perform their own role in the order of reality to provide moral knowledge that brings in morality to the works of scientists.

\section{Religious knowledge}

Religious and theological knowledge - as Audi (2003:278) notes - 'are beyond the scope of human understanding'. Faith and revelation serve as the religious method of inquiry which is not, and cannot be, scientific in nature. With the aid of faith and revelation coupled with the gift of mystical experience, theists, spiritual masters and theologians are able to understand supernatural realities that are beyond scientific understanding. One cannot demean religious knowledge on the grounds that the spiritual cannot be empirically verified. Incidents like the mysterious survival of a terminally ill person, magical experiences and the many miraculous events in the universe show that there are many issues that are beyond scientific understanding and explanation.

Although religious knowledge of a Supreme Being is based on faith and revelation, it can stem from common sense or a rational consideration of the existence of the universe. Contrary to the claims of Hawking and Dawkins that there is no Supreme Being as apparently extrapolated from the Big Bang theory and the evolution theory, the existence of the universe continually leads to the quest for a sufficient reason for its existence. Based on reason, one can arrive at the reality of a Supreme Being who gives the universe a sufficient reason for its existence. Upon observing the changes in the universe and 'the premise that there cannot be an infinite chain in the causes of motion one comes to conclude that a Supreme Being, the Unmoved First Mover, exists' (Audi 2003:278). Here, religious believers attach transcendental attributes to the Supreme Being who gave the universe its 'being' with the possibility of becoming everything that it was, is and shall ever be.

Despite scientific efforts to determine the origin of the universe without recourse to a creator, scientists cannot claim to be certain of their claims because their view is limited. Such considerations led Aquinas to insist revelation and/or belief are the only means to understand the beginning of the universe (Jaki 2000:103). Science has continually failed to:

demonstrate the transition from non-existence to the existence of the atom that exploded during the Big Bang. The comprehension of the origin of the universe is far from scientific comprehension because scientists cannot go outside the universe to observe the whole of it and give a supreme objective and genuine knowledge about it. (Ani 2013:312) 
Hence, efforts to define the whole through the knowledge of some aspects of reality remain deficient and mythological because it is an imaginary, reductive and idealistic conception of reality that is constituted of matter alone. So, with which yardstick should we endorse scientific dogmatic mythology over other mythologies?

This, thus, highlights the contention of this study which advances pluralistic epistemology. As science provides knowledge about material entities, religion provides insights on spiritual and moral aspects. Lehar (n.d.) contends that:

religion offers a system of values, right and wrong, good and evil, a code of morality, and that is why even many scientists choose a religious belief to guide their lives. Although science is unquestionably the best tool to answer any question one might choose to ask, science offers no hint as to which questions are important to ask. Questions of value are totally outside the scope of science. (p. 2)

\section{Poetic and artistic knowledge}

Poetic and artistic knowledge derive from imaginations and emotions that do not require experiments and scientific reasoning (Maritain 1953:17). Poets and artists present their imaginations, feelings, ideas and creativity in a piece of work. Over the years, noble ideas and magnificent things have been invented and discovered using imagination. For instance, aircrafts, phones, satellites and the immense discoveries that are made by scientists come from a good use of imagination that is not limited by the bounds of visible reality. Modern science owes its idea of atom to the imaginative philosophy of the ancient Greek atomists. The Big Bang and the evolution theories tend to serve as continuations of the imaginative quest of the ancient philosophers who sought to discover the basic stuff out of which everything emerged. Thus, the imaginative knowledge of poets and artists as expressed in their work is profound, and not to be merely considered unscientific and unintelligible. Science is not meant to be a standard through which all knowledge is measured.

If scientism is to be taken seriously, consciousness, feelings, knowledge, free will, purpose, morality, responsibility, reactions to jokes or the extent to which a word makes meaning to an individual will be considered non-existent and empty since it can neither be seen nor measured scientifically. Despite the fact that science cannot prove the aforementioned realities, we are not to claim that the aforementioned realities do not exist because they cannot be explained scientifically. Other fields of knowledge can approach these issues and provide better knowledge of them. Jaki (2000:19) asserts that 'human knowledge comes from two realms, quantities and non-quantities, and these two realms are irreducible to one another'. The world is much more than what can be tested.

\section{Conclusion}

Thus far, the paper has argued that scientism is based on the unfounded view of science as the epitome of genuine knowledge. The paper highlighted the nature and limits of science which make the claims of scientism untenable. Although science has undoubtedly led to remarkable advancements in human history, the paper observes that the objectivity of science is subject to question like other forms of knowledge. It also considered the valid grounds that justify the operation of other fields of study like philosophy, religion, poetry and art.

Every particular field of knowledge like philosophy, theology, poetry, arts and social studies - including science approach reality from a certain perspective and each field of knowledge can claim the superiority and validity of its method of inquiry only with regard to its own subjectmatter. Hence, different fields of knowledge with their distinctive ways of knowing show that human knowledge is not univocally reserved for natural sciences or any particular field of knowledge. As such, a more pluralistic and complementary approach in epistemology is vital for holistic human advancement.

\section{Acknowledgements Competing interests}

The author declares that he has no financial or personal relationships which may have inappropriately influenced him in writing this article.

\section{References}

Alexander, D., 2008, Creation or evolution: Do we have to choose? Monarch Books, Oxford.

Ani, N.C., 2013, 'Appraisal of African Epistemology in the Global System', Alternation 20(1), 295-320.

Audi, R., 2003, Epistemology: A contemporary introduction to the theory of knowledge, Routledge, New York.

Barrett, P., 2000, Science and Theology since Copernicus: The Search for Understanding, Unisa Press, Pretoria.

Capra, F., 1982, The Tao of Physics: An Exploration of the Parallels between Modern Physics and Eastern Mysticism, Flamingo, London.

Carlo, E.W., 1967, Philosophy, science and knowledge, The Bruce Publishing Company, Milwaukee, WI.

Collinson, D., 1987, Fifty major philosophers, Routledge, New York.

Copleston, F., 1963, A history of philosophy (Vol. 3): Late mediaeval and Renaissance philosophy (Pt II), A Division of Doubleday and Company, Inc., New York.

Dauben, J.W., 1987, The World Book encyclopedia, vol. 17, World Book, Inc., Chicago, IL.

Dawkins, R., 2006, The God Delusion, Cox and Wyman Ltd, Berkshire.

Descartes, R., 1641, Discourse on method and the meditations, transl. F. E Sutcliffe, Penguin Books, New York.

Gilson, E., 1963, Modern philosophy: Descartes to Kant, Random House, New York.

Gleiser, M., 2014, The Island of knowledge: The limits of science and the search for meaning, Basic Books, New York.

Hawking, S., 1988, A brief history of time, Bantam Press, London.

Hazen, R.M. \& James, T., 1996, Science matters, Universities Press, Hyderabad.

Hummel, C.E., 1986, The Galileo connection: Resolving conflicts between science and the Bible, Inter Varsity Press, Westmont, IL.

Jaki L.S., 2000, The limits of the limitless science, ISI Books, Wilmington, DE.

Jones, W.T., 1975, A history of Western philosophy: Kant and the nineteenth century, 2nd edn., revised, Harcourt Brace Jovanovich, Publishers, San Diego, CA.

Kant, I., 1929, Critique of pure reason, transl. N.K. Smith, Macmillan Press, London.

Kuhn, T.S., 1962, The structure of scientific revolutions, 2nd edn., Thee University of Chicago Press, London.

Lehar, S., n.d., Scientism: A system of ethics based on reason without recourse to supernatural belief, viewed 20 February 2016, from http://cns-alumni.bu. edu/ slehar/Scientism.pdf

Maritain, J., 1953, The range of reason, Geoffrey Bles, London.

Midgley, M., 2006, Science and poetry, Routledge Classics, London. 
Miller, K.R., 1999, Finding Darwin's God, Harper Collins Publishers, Sidney.

Neill, T.P., 1958, Makers of the Modern Mind, The Bruce Publishing Company, Milwaukee.

Newton, I., 1987, Principia: Philosophiæ Naturalis Principia Mathematica, Benjamin Motte, London.

O'Hear, A., 1989, An introduction to the philosophy of science, Clarendon Press, Oxford.

Polkinghorne, J., 1996, Beyond science: The wider human context, Cambridge University Press, Cambridge.

Popper, K., 1972, The logic of scientific discovery, Hutchinson and co. Ltd, London.
Sahakian, W.S., 1968, History of philosophy, Barnes and Noble, Inc., London. Sanguineti, J.J., 1987, Logic and gnoseology, Urbaniana University Press, Bangalore. Solomon, R.C. \& Higgins, K.M. (eds.), 1996, A short history of philosophy, Oxford University Press, New York.

Sorell, T., 1991, Scientism: Philosophy and the infatuation with science, Routledge, London.

Stumpf, S.E., 1982, Socrates to Sartre, McGraw-Hill Book Company, New York.

Thornton, S., 2008, 'Karl popper', in N.Z. Edward (ed.), The Stanford encyclopedia of philosophy (Fall 2008 edition), viewed 14 June 2008, from http://plato.stanford. edu/archives/fall2008/entries/popper/ 